\title{
LA RESPONSABILIDAD DE FUNCIONARIOS (EL JUICIO POLÍTICO)
}

\author{
GONZALES OJEDA, Magdiel ${ }^{126}$
}

SUMARIO: 1. Introducción. - 2. La función pública. - 3. El control político del Estado. - 4. El juicio político. - 5. El juicio político en la Constitución nacional.

\section{Introducción}

El desenvolvimiento del Estado supone transitar por los caminos previstos por la Constitución Política. Se trata de que el Estado funcione, pero dentro del marco constitucional, que se cumpla con los principios y disposiciones de la Constitución, se respete el orden constitucional tanto en el ejercicio responsable de las funciones públicas por parte de los operadores estaduales como en el funcionamiento de las instituciones políticas del Estado.

La Constitución Nacional en su artículo $45^{\circ}$, determina que el poder emana del pueblo, se trata de uno de los principios fundamentales del liberalismo clásico que quiere significar que el pueblo mediante su voluntad social funda el Estado y le otorga potestades y facultades para administrar y gobernar, en el marco de un sistema jurídico y por medio de órganos estaduales denominados instituciones Políticas del Estado. Este acto fundacional supone, también, la elección de las personas depositarias del poder, o representantes de la voluntad social, todo lo que configura los principios más importantes del Estado moderno, el de ser representativo y democrático, por cuanto nuestro Estado Republicano se basa en la soberanía popular.

Conformado el Estado, el poder es manejado por los operadores políticos, ellos realizan sus funciones dentro de los límites del orden constitucional y legal. En este entorno, el poder resulta la facultad de operar que tienen los representantes del pueblo, con el propósito de alcanzar los fines propuestos dentro del modelo social. Por funciones se denomina a esta facultad de operar, que se le asigna a los representantes de la voluntad popular, mediante los repartos consignados en la Constitución o la Ley; por lo tanto, este poder no es ilimitado, menos aún, permite el libre albedrío en el manejo constitucional por más alto nivel de la función asignada; éste es el contenido que nos trae la fórmula de artículo $45^{\circ}$ de nuestra Constitución; en otras palabras, se trata de reconocer en el pueblo la fuente originaria del poder, poder que también debe ser reconocido como la fuerza social ${ }^{127}$ encaminada a dar forma político-jurídica y estructura económica a ese grupo social, para lo cual se desarrolla el proceso que supone: $1^{\circ}$ La instalación o nombramiento de los depositarios del Poder; $2^{\circ}$ El reparto de las funciones entre los redistribuidores del poder, o

${ }^{126}$ Presidente de la Comisión encargada del Funcionamiento de la Facultad de Derecho y Ciencia Política de la Universidad Ricardo Palma; Doctor en Derecho Público por la Universidad Nacional San Agustín de Arequipa. Ex Vicepresidente del Tribunal Constitucional.

${ }^{127}$ BIDART CAMPos, Germán. El Poder, EDIAR Bs. Aires 1985, p. 30. 
diseño del orden político; y $3^{\circ}$ Regulación y limitación apropiada del ejercicio del poder o formulación del orden jurídico (principio en el cual reposa el Estado de Derecho).

En este marco, surge el Parlamento como la institución más importante para preservar el orden político jurídico del Estado, cuidar la vigencia real de los Derechos Fundamentales y prever la materialidad necesaria para alcanzar las metas sociales expresadas en el Modelo Social. Su función principal es asegurar que la dirección política de la comunidad se lleve a cabo de acuerdo a las aspiraciones del titular de la soberanía, la que supone necesariamente el control de los representantes parlamentarios sobre la acción del Gobierno ${ }^{128}$.

En nuestro caso el legislador histórico nacional, desde los albores de la República, se ocupó de fijar los límites de las funciones del Poder Ejecutivo; y ese fue el sentido del Reglamento Provisional del Poder Ejecutivo (Ley del 15 de octubre de 1822). En dicho Reglamento se establecían las obligaciones del Poder Ejecutivo en las relaciones con el Congreso, así como en las relaciones con el Poder Judicial, en las finanzas públicas y el orden interno. De igual manera, en las Bases Constitucionales de la Constitución Política de la República del Perú, de 16 de diciembre de 1822, que constituyen los principios que orientan la Constitución Formal del Estado y sintetizan la voluntad permanente de la nación; se determinó que como garantía de la libertad es necesario el establecimiento del principio de la división de las principales funciones del poder nacional, haciéndolas independientes unas de otras en cuanto sea dable.

Dichos principios, permanentes y vigentes, se encuentran no sólo en la Constitución Material, están también explícitos o implícitos en todas las Constituciones Formales que el país ha tenido y tiene juntamente con el Modelo Social de la Nación (que asume similares características de los principios en cuanto a su presencia constitucional), que magistralmente sintetiza el maestro Jorge Basadre ${ }^{129}$, cuando precisa los objetivos doctrinarios de la Patria: una nación libre y soberana, ciudadanía digna, Estado legal y eficiente y sociedad próspera; que son los parámetros obligatorios para toda función de control.

Los llamados operadores supremos son los responsables de la conducción política del Estado, dentro de los principios que dicta la Constitución Nacional para que la Nación alcance sus metas sociales, que el Modelo Social sea una realidad, que el pueblo se realice en una sociedad democrática, con justicia y respeto a los Derechos Fundamentales. Esta actividad, los órganos supremos del Estado y la relación vinculante con la Nación, definen precisamente la Función Pública.

\section{La Función pública}

Con Hans Kelsen ${ }^{130}$, la clásica concepción de la "División de los Poderes ", ha sido sustituida por el concepto de la unidad del Poder estatal, ahora de se habla de un sólo poder del Estado, el Poder Político; señala que el poder del Estado es unitario e indivisible, se compone, sin embargo, de tres poderes coordinados, se trata de una distribución técnica de los tres poderes o funciones entre tres órganos o grupos aislados unos de otros y jurídicamente independientes. En este marco conceptual, el Estado para cumplir con sus fines realiza sus actividades a través de las funciones legislativas, ejecutivas o jurisdiccionales.

${ }^{128}$ Montero Gibert, José y García Morillo, Joaquín. El Control Parlamentario,. TeCNOS. Madrid 1984, p. 126.

${ }^{129}$ BASADRE, Jorge. Historia de la República del Perú. Ed. Universitaria. T1. Lima 1983, p. 187.

${ }^{130}$ KeLSEN, Hans. Teoría General del Estado. Editora Nacional, México, 1970. p. 334. 
Con estos antecedentes podemos decir que para Kelsen el aspecto dinámico del Estado se realiza a través de la Función Pública conforme a las potestades determinadas por el orden jurídico.

Con este criterio, el cual compartimos, la Función Pública no se refiere al régimen del funcionario público, mucho menos a las personas que reciben una remuneración de los fondos públicos. La Función Pública, es una institución prevista en el orden constitucional, en tal razón, no podemos limitar su estudio al ámbito o actividad del funcionario público, del empleado público; se trata más bien la de la institución en sí, cuyas coordenadas no se encuentra en el campo del Derecho Administrativo, el Derecho Constitucional y a la Teoría del Estado la regulan y la determinan. Pues el funcionario público realiza una función administrativa y la ejerce dentro legal y conforme lo acuerda la ley y dichos actos son calificados como voluntad de la administración.

La Función Pública, institución del Derecho Público, es una actividad que en el ordenamiento constitucional se reserva a los órganos supremos del Estado, y que está referida, también, en forma vinculante a los destinatarios de la Función Pública, esto es, a la nación en términos de igualdad; de donde podemos colegir que la responsabilidad en la Función Pública sólo puede ser atribuida a determinados operadores estaduales, es decir a los operadores supremos como el Presidente de la República, a los representantes al Congreso, a los Ministros de Estado, a los Magistrados del Tribunal Constitucional, a los Miembros del Consejo Nacional de la Magistratura, a los Magistrados de la Corte Suprema, a los Fiscales Supremos, al Defensor del Pueblo y al Contralor de la República.

\section{El control político del Estado}

El control político del Estado lo ejerce el Parlamento que -se supone- es el depositario de la voluntad popular, con lo que adquiere gran relevancia este control. Su actividad cuida posibilitar el cumplimiento de las tareas y funciones del complejo orgánico funcional del Estado. Se trata de un control que se da como expresión de la voluntad popular. Esta función suprema del Control Político es ejercida por mandato constitucional a través del Parlamento, quien como representante de la voluntad social debe cuidar en todo momento la real vigencia del orden jurídico-político, el respeto a los Derechos Fundamentales y que se alcance el Modelo Social.

El Control Político como función fundamental del Parlamento, lo supone un cierto desplazamiento en importancia a la función legislativa; el Parlamento debe realizar permanentes constataciones en todos los ámbitos del Estado, sean públicos o privados, para ver si se cumplen con lo dispuesto por el orden constitucional y especialmente con el modelo social adoptado por la voluntad social, sí se respeta el orden jurídico, sí funciona debidamente el orden político, si el Estado cumple con los fines definidos en la Constitución.

El Control Político que debe realizar el Parlamento tiene que hacerlo a través de las comisiones ordinarias o las especiales a que se refiere la Constitución en su artículo $97^{\circ}$, que autoriza al Congreso iniciar investigaciones sobre cualquier asunto de interés público. Abierta la investigación es obligatorio comparecer, por requerimiento ante la comisión encargada de la investigación, bajo los mismo apremios que se observan en el procedimiento judicial. Pero además, dichas comisiones pueden acceder a cualquier información; excepto la información que afecte la intimidad personal. Estas comisiones tienen amplias facultades para esclarecer los asuntos que afectan al orden democrático y ético del país. 


\subsection{Noción de control político}

Con mucha razón, el hombre desconfía de todo poder ilimitado ${ }^{131}$; por lo que siempre se ha preocupado por diseñar mecanismos para limitar y controlar el poder y el orden social. La democracia debe contar con todos los elementos e instrumentos necesarios para su defensa, como parte del poder para la conservación del Estado y sus instituciones, nos dice Vanossi ${ }^{132}$. Se trata de contar con medidas que la nación se impone a sí misma y a los operadores del poder, medidas que se factibiliza en un sistema de reglas fijas, aprobadas por la voluntad social a través del Poder Constituyente.

En la función del Control Político subyace la facultad de exigir la responsabilidad política a los operadores del poder, y a los ciudadanos el respeto al orden constituido; función que se inicia con la investidura que el legislativo otorga al Consejo de Ministros (artículo $5^{\circ}$ del Reglamento del Congreso). Así, la nación dentro el poder constituido, tiene en el Control Político el instrumento más importante del control del Estado. En la democracia es la técnica más eficaz para limitar el poder y controlar especialmente al operador ejecutivo.

La denominación, para nosotros, surge del órgano encargado del Control, así como de la actividad regulada y de las connotaciones inéditas de actividad o función materia del Control. Se trata en primera instancia de una exigencia sobre la responsabilidad del operador estatal controlado, la misma que en un primer orden de supervisión es de carácter político.

En tal sentido, podemos hablar de control político como función del Parlamento, tanto por su naturaleza de institución suprema conformante del poder político, como también por las funciones que realiza, pues tiene la facultad constitucional de determinar la responsabilidad política de todos y cada uno de los operadores estatales, en el momento oportuno; es la actividad del Ejecutivo, fundamentalmente, el objeto del control. Los efectos del control son plurales, jurídica y políticamente, siendo el de la remoción del equipo gubernamental sólo uno de ellos ${ }^{133}$.

El control político se define, entonces, como función esencial del Parlamento destinada a preservar la vigencia y funcionamiento del orden político-jurídico del Estado, cuida asimismo del respeto de los Derechos Fundamentales y de la consecución de las metas nacionales expresadas en el Modelo Social.

\subsection{El Congreso Nacional titular del control político}

El Congreso Nacional, expresión más inmediata de la voluntad de la Nación, artículo $93^{\circ}$ de la Constitución, asume por principio y mandato constitucional el Control Político del Estado, pues está obligado a confrontar los actos de los operadores estaduales y en general de todas las personas con la Constitución, tienen que verificar si están de acuerdo con ella o, en su defecto, disponer las medidas correctivas sin perjuicio de las responsabilidades a que haya lugar, artículo $102^{\circ} .2$, de la Constitución.

EL principio de la Supervisión de las funciones supremas del Estado (separación de poderes) supone la existencia del poder limitado por el poder, mediante el conocido sistema

\footnotetext{
${ }^{131}$ LoewwnsteIn, Karl. Teoría de la Constitución. Ed. Ariel. Bs. Aires 1979, p. 68.

${ }^{132}$ VANOSSI, Jorge Reynaldo, Democracia Constitucional, Pluralismo y Control. En varios. El Control Parlamentario en las Democracias Pluralistas. Ed. LABOR. Barcelona 1978, p. 20.

${ }^{133}$ Montero GiBert, José y García Morillo, Joaquín. Ob. cit. p. 32.
} 
de frenos y balances o contrapesos que imponen un equilibrado ejercicio del poder. Este equilibrio se logra básicamente con el control político; dicho principio se encuentra formalizado en nuestra Constitución Política en su artículo $43^{\circ}$, que prescribe que el gobierno del Perú se organiza según el principio de la separación de los poderes.

El Congreso Nacional conforme a lo disponen los artículos $96^{\circ}, 97^{\circ}$ y $99^{\circ}$ de la Constitución y los artículos $2^{\circ}$ y $5^{\circ}$ de su Reglamento, modificado por el Pleno del Congreso de fecha 6 de marzo de 1998, es titular del Control Político del Estado; en tal razón, le corresponde la investidura del Consejo de Ministros, el debate, la realización de actos e investigaciones y aprobación de acuerdos sobre la conducta política del Gobierno. Le corresponde igualmente, conocer los actos de la administración y de los actos de autoridades del Estado, el ejercicio de la delegación de funciones, el uso y disposición de bienes y recursos públicos, el discurso anual del Presidente de la República ante el Congreso y el ante juicio o juicio político; todo ello, cuidando que la Constitución Política y las leyes se cumplan y disponiendo lo conveniente para hacer efectiva la responsabilidad de los infractores.

Conforme a las facultades asignadas al Congreso Nacional en el Marco de la Supervisión, vía Constitución o Reglamento del Congreso, podemos afirmar que la función del Control Político del Estado, cuyo titular es el Congreso de la República, trasciende las relaciones Parlamento-Ejecutivo, aunque su núcleo se encuentre en dichas relaciones, es decir, que su ámbito de trabajo no se agota en estas relaciones, incluso sus límites están más allá del sector público, pues ingresa al sector privado cuando los actos o hechos que allí se dan se definen como de interés público, artículos $97^{\circ}$ y $102^{\circ} .2$ de la Constitución vigente.

\subsection{Tipos de control político}

El Control Político, vigilancia que asume el Congreso de la República por decisión de la voluntad social, artículo $93^{\circ}$ de la Constitución y $2^{\circ}$ del Reglamento del Congreso, para cuidar que las decisiones que se adopten a nivel de la administración del Estado y la conducta de las personas del sector privado no atenten el orden establecido ni obstruyan la marcha normal del Estado en la consecución de las metas sociales.

Dicho control está referido tanto al examen de las funciones estaduales como al origen de los operadores del Estado; en tal razón es obligación permanente del Congreso de la República exigir a todos los operadores estaduales -específicamente a los supremos- el cumplimiento responsable de sus funciones, de igual manera, demanda también a las personas el respeto del orden constituido. En efecto, la Constitución determina que el Congreso, entre otras funciones, asuma especialmente las del Control Político; control que está destinado a garantizar los bienes tutelados por nuestra ley fundamental. Se pretende asegurar y proteger la Soberanía Nacional, la vigencia de los Derechos Fundamentales y la Seguridad de la Nación, así como alcanzar el Modelo Social pero con justicia, artículo $44^{\circ}$ de la Constitución.

La función del Control Político del Congreso supone asegurar que la política general del gobierno y las principales medidas que se adopten sean coherentes con el orden Constitucional, artículos $130^{\circ}$ y $118^{\circ} .7$ de la Constitución; implica igualmente el control sobre las potestades normativas del Ejecutivo, especialmente sobre los Decretos de Urgencia y la Legislación Delegada, artículos $118^{\circ} .19$ y $104^{\circ}$, en estos casos, por mandato constitucional y en cumplimiento del principio de Separación de las Funciones Supremas del Estado, el Ejecutivo tiene la obligación de dar cuenta al Congreso sobre tales normas y los 
hechos que han determinado su promulgación. Todo ello para el examen correspondiente del Congreso, el que puede derogar o modificar las referidas normas.

De la misma manera, la Constitución nacional en su artículo $137^{\circ}$, establece el Control Político con respecto a los Decretos Supremos mediante los cuales el Ejecutivo dicta u ordena los estados de Excepción. El control cuida también la celebración válida de los tratados Internacionales, conforme a los artículos $56^{\circ}$ y $57^{\circ}$ de la Constitución. En general, como se tiene expuesto, es obligación del Congreso velar por el respeto a la Constitución, que los operadores del Estado cumplan debidamente con sus funciones, que las personas asuman a cabalidad los deberes establecidos en el artículo $38^{\circ}$ de la Constitución nacional, que los bienes y recursos de la Nación y del Estado sean debidamente utilizados.

Toda esta actividad se realiza a través de un conjunto de prácticas institucionalizadas que se encuentran formalizadas en nuestra Constitución Nacional, tales como la Investidura del Consejo de Ministros, el Juicio Político, la Interpelación, la Censura, las Comisiones Investigadoras, las Mociones del orden del día, así como la Defensoría del Pueblo.

\section{El juicio político}

El Juicio Político es un procedimiento destinado a establecer la responsabilidad que le corresponde a ciertos funcionarios públicos u operadores supremos del Estado; se trata de los principales operadores de las funciones ejecutivas, legislativas y jurisdiccionales, por hechos, actos u omisiones realizados durante el período de su gestión y cuyo fin es separarlos de su cargo o suspenderles sus prerrogativas o inmunidades y ponerlos a disposición del órgano jurisdiccional del Estado.

El Juicio político es, pues, el fallo que pronuncia un cuerpo político momentáneamente revestido del derecho de juzgar ${ }^{134}$, cuya finalidad, como lo señala el Dr. Ortecho $^{135}$, es contener el exceso y el abuso del poder y, de esta manera, resguardar el derecho de los ciudadanos que son los que sufren las consecuencias. Este procedimiento está dirigido a la revocatoria del mandato, ya que tiene por objeto privar al operador estatal de la función que desempeña, sin perjuicio de someterlo a la jurisdicción judicial, según sean los hechos generadores de su responsabilidad jurídica ${ }^{136}$.

El instrumento más significativo de control que tiene el Parlamento sobre los poderes Ejecutivo y Judicial, es el Juicio Político, nos afirma el profesor argentino Néstor Pedro Sagües ${ }^{137}$. Efectivamente, por principio constitucional los funcionarios públicos responden por sus actos a los titulares del poder; en otras palabras, están sujetos al control de la Nación. Pero dentro del Poder Constituido, en el marco del Estado Moderno, el Parlamento, por su carácter representativo, se constituye como mandatario de la nación y en tal razón resulta el titular del Control Político.

\footnotetext{
${ }^{134}$ Tocqueville, Alexis de. La Democracia en América. Ed. Fondo de Cultura Económica. México 1987, p. 112. Trujillo, p. 15.

${ }^{135}$ Ortecho VILlenA, Víctor Julio. Juicio Político y Procesos a Funcionarios. Ed. LIBERTAD.

${ }_{136}$ BIELSA, Rafael. Derecho Constitucional. Ed. DEPALMA Bs. Aires, 1959, p. 481.

${ }^{137}$ SAgúEs, Néstor Pedro. Elementos de Derecho Constitucional. T-I. Ed. Astrea. Bs. Aires, 1993, p. 514.
} 
En los actos de los operadores estaduales, no sólo se considera la responsabilidad civil o penal, se tiene en cuenta en primer lugar la responsabilidad política o mal desempeño de sus funciones y se tangibiliza dicha responsabilidad en un procedimiento político, ya que se verifica en una institución netamente política como es el Parlamento. Este es un criterio muy difundido y aceptado en la mayoría de los Estados, en general se sostiene que para el juicio de algunos delitos de contenido típicamente político cometidos por el jefe de Estado, o por los ministros, los procedimientos ordinarios no son oportunos ni son idóneos los órganos judiciales normales, por lo que debe recurrirse a la función de Control Político que tiene el Parlamento.

\subsection{Naturaleza del juicio político}

El tránsito por los predios de esta institución es muy conflictivo; pues, se debate si el Juicio Político tiene carácter de proceso jurisdiccional o exclusivamente político, o participa de ambos criterios; no se tiene una opinión uniforme en cuanto a la naturaleza del juicio político. Pero sí hay cierto consenso en cuanto a que se trata de una institución o mecanismo que cuida la estructura política del Estado y su funcionamiento sea conforme a lo dispuesto por la Constitución.

Para Bielsa ${ }^{138}$, el Juicio Político se desarrolla en un campo no muy definido; el procedimiento participa del ámbito común, tanto civil como penal, como también y también el político y administrativo. Mientras que para el Dr. García Belaúnde ${ }^{139}$ tal institución tiene un carácter más bien político, al señalar que en realidad se trata de un antejuicio que se realiza en las Cámaras Legislativas.

Por su parte, Alexis de Tocqueville ${ }^{140}$ dice que en Europa el Juicio Político es un acto judicial, allí los tribunales políticos pueden aplicar todas las disposiciones del Código Penal; en tanto que en los Estados Unidos es un acto administrativo al que se ha dado la solemnidad de una sentencia. Recientemente Biscaretti di Ruffía ${ }^{141}$ sostiene que, después de la Primera Guerra Mundial, se ha considerado que la intervención del Parlamento sólo está circunscrita a determinar si procede o no juicio contra el operador acusado y en tal caso los antecedentes deben ser pasados a los órganos jurisdiccionales; por tanto, la función que hoy queda al Parlamento es el examen político de los hechos. En este caso, dice Biscaretti, se asemeja a la función del Ministerio Público, en cuanto no juzga sino que se limita a solicitar del magistrado la realización de la función jurisdiccional, es decir, estamos frente a lo que el maestro García Belaúnde llama antejuicio, cuyo carácter es netamente político y no jurisdiccional.

Javier Valle-Riestra ${ }^{142}$ nos dice que el Juicio Político no es un procedimiento judicial, aunque durante el proceso se sigan leyes adoptadas para el funcionamiento de los tribunales ordinarios; pero de allí no se puede llegar a considerársele como un procedimiento judicial. Se trata de una institución de naturaleza eminentemente política, a pesar de que dentro del proceso encontremos elementos de Derecho Penal o Administrativo; ya que la posibilidad o

\footnotetext{
${ }^{138}$ BIELSA, Rafael. Ob. Cit., p. 596.

139 GARCÍA BElaUnde, Domingo. Sistema Constitucional Peruano. En varios. Los Sistemas Constitucionales Americanos. Ed. Dykinson, Madrid, 1992, p. 729.

${ }^{140}$ TOCQUeVILle, Alexis de. Ob. cit., p. 113.

${ }^{141}$ BisCARETTI DI RUfFIA, Paolo. Derecho Constitucional. Ed. Tecnos. Madrid 1987, p. 417.

${ }^{142}$ VALlE-RIESTRA, Javier. La Responsabilidad Constitucional del Jefe de Estado. ed. LABRUSA,
} Lima, 1988, p. 65. 
el dictado de una pena no puede llevarnos a la conclusión de que el Juicio Político sea de naturaleza jurisdiccional, más aún si la inhabilitación del operador estatal procesado es más una sanción moral que una pena. Pero tampoco puede decirse que se trata de un procedimiento administrativo, cuando se concluye con la suspensión de los fueros del operador así como su inhabilitación para el cargo, ya que no se trata de una sanción disciplinaria contemplada y exigida internamente en la Administración Pública, y los operadores comprendidos en el Juicio Político generalmente están premunidos de potestad.

El Juicio Político es un proceso político previo a la vista jurisdiccional, cuya naturaleza es política tal como lo sostiene Summer ${ }^{143}$, senador norteamericano que en el año de 1867, con ocasión del impeachment al Presidente Andrew Johnson, decía que en su verdadero carácter, el Juicio Político, es un procedimiento político, con propósitos políticos, cuya consideración incumbe a un cuerpo político y tan sólo está subordinado a un juzgamiento político. Aun en los casos de traición y soborno, el juzgamiento es político y nada más.

\subsection{Operadores estaduales comprendidos}

La Constitución Nacional vigente, en su artículo $99^{\circ}$, determina que la Comisión Permanente del Congreso puede acusar ante el Pleno de dicho cuerpo colegiado al Presidente de la República, a los Congresistas, a los Ministros de Estado, a los miembros del Tribunal Constitucional, a los miembros del Consejo Nacional de la Magistratura, a los Vocales de la Corte Suprema, a los Fiscales Supremos, al Defensor del Pueblo y al Contralor General de la República por infracción de la Constitución y por todo delito que cometan en el ejercicio de sus funciones. Como veremos más adelante, la acusación constitucional se realiza según procedimiento dispuesto en el artículo $89^{\circ}$, del Reglamento del Congreso.

En tal razón, las personas comprendidas o que pueden ser comprendidas en Juicio Político son solamente los señalados en dicha norma constitucional, es decir, todos los operadores incluidos en el artículo $99^{\circ}$ de nuestra Ley Fundamental. Además, la Constitución de 1993 es tajante en precisar que dichos operadores pueden ser acusados hasta cinco años después de que hayan cesado en el ejercicio de sus funciones.

\subsection{Causales que dan lugar a juicio político}

En la Constitución Nacional, como en la mayoría de la legislación constitucional comparada, se encuentra dos hipótesis como causales que pueden dar lugar a Juicio Político; efectivamente, en su artículo $99^{\circ}$, se ordena iniciar el procedimiento contra operadores supremos del Estado, por infracción a la Constitución y por todo delito que cometan en el ejercicio de sus funciones:

a) Infracción a la Constitución. En este presupuesto estamos frente a un concepto muy lato que permite un juicio discrecional, demasiado amplio. Se trata de la transgresión o quebrantamiento del orden constitucional, sea por acción u omisión dolosa o culposa, o también por falta de idoneidad no sólo profesional o técnica, sino también ética como la ineptitud, la insolvencia moral, todo lo cual determina un daño a la función, o sea, a la gestión de los intereses de la nación ${ }^{144}$.

${ }^{143}$ GonZales Calderón, Juan A. Curso de Derecho Constitucional. Ed. KRAFT, Bs. Aires, 1943, p. 775.

${ }^{144}$ BIELSA, Rafael. Ob. cit., pág. 600. 
b) Delitos Cometidos en el Ejercicio de sus Funciones. Ahora sí nos encontramos con una causal concreta, objetiva, porque la conducta del operador define una trasgresión legal, se trata de un hecho ilícito, aunque de él no resulte un daño material o patrimonial (daño jurídico) para la nación, nos explica Rafael Bielsa ${ }^{145}$.

\section{El juicio político en la constitución nacional}

El juicio Político en el Perú tiene como antecedente más lejano el juicio republicano de residencia que persistió hasta la Constitución de $1860^{146}$. La Constitución de 1860 excluyó de la legislación nacional la vieja institución colonial del Juicio de Residencia y dio paso al Juicio Político. De toda forma, en el Perú republicano el Parlamento siempre contó con los mecanismos de control sobre el Ejecutivo. Así, desde las Bases Constitucionales de 1822 hasta la Constitución vigente hemos contado y contamos con instituciones que permiten al Congreso tener los mecanismos necesarios para establecer y hacer efectiva la responsabilidad de los operadores estaduales por infracción de la Constitución o delito o falta cometida en el ejercicio de sus funciones. Sin embargo, en nuestra historia constitucional encontramos una excepción al respecto que nos trae la Constitución Vitalicia de 1826, pues exoneró de responsabilidad política al Presidente vitalicio de la República.

Las Bases Constitucionales de 1822, que definen los principios que se deben formalizar en la Constitución Nacional, determinaban en su artículo $15^{\circ}$, la responsabilidad solidaria entre los que ejercen el Poder Ejecutivo y los Ministros de Estado, por las resoluciones tomadas en común. De igual manera, en su artículo $16^{\circ} .1$, señala la atribución del Senado de cuidar la observancia de la Constitución y las leyes, así como velar la conducta de los magistrados y de los ciudadanos.

De esta manera, las Bases Constitucionales incorporan en la Constitución Nacional dos instituciones muy importantes: la responsabilidad solidaria y personal de los operadores supremos del Estado y la facultad del Congreso de cuidar el orden constitucional. Este criterio va ser mantenido hasta la Constitución vigente, claro está con avances y retrocesos.

\subsection{Procedimiento en el juicio político}

El juicio político, procedimiento parlamentario previsto en nuestra Constitución en sus artículos $99^{\circ}$ y $100^{\circ}$, está destinado a establecer la responsabilidad que les corresponde a ciertos funcionarios supremos del Estado por infracción de la Constitución y por todo delito que cometan en ejercicio de sus funciones y hasta cinco años después que hayan cesado en sus cargos. De las normas citadas y del artículo $89^{\circ}$ del Reglamento del Congreso de la República, podemos señalar que el procedimiento del juicio político o antejuicio se integra básicamente de dos etapas, la de acusación y la de resolución acusatoria o formación de causa; asimismo, que el acusado tiene el derecho a la defensa en todas las etapas.

\footnotetext{
${ }^{145}$ Loc. cit.

${ }^{146}$ ORTECHO VILLENA, Víctor Julio. Ob. cit., p.22.
} 


\subsection{La Acusación Constitucional}

Conforme al artículo 99 $9^{\circ}$, de la Constitución Nacional, corresponde a la Comisión Permanente acusar ante el Congreso al Presidente de la República, a los Congresistas, a los Ministros de Estado, a los Magistrados del Tribunal Constitucional, a los Miembros del Consejo Nacional de la Magistratura, a los Vocales de la Corte Suprema, a los Fiscales Supremos, al Defensor del Pueblo y al Contralor General por infracción a la Constitución y por todo delito que cometan en ejercicio de sus funciones.

Esta etapa se realiza en dos fases, la de denuncia y la de acusación. La primera fase se refiere a la presentación, recepción y calificación de las denuncias constitucionales. En efecto, cualquier persona o congresista que se considere agraviada puede presentar denuncia constitucional contra los operadores supremos del Estado a que hace referencia el artículo $99^{\circ}$ de la Constitución vigente.

La denuncia se presenta por escrito, la que se pone en conocimiento de los Congresistas hasta por siete idas útiles a través de los grupos parlamentarios, y un resumen de la denuncia se lee en la sesión del Pleno o de la Comisión Permanente. Transcurrido el plazo sin que ningún Congresista haga suya la denuncia, ésta será enviada por el Oficial Mayor del Congreso a una Comisión Especial Calificadora integrada por cinco o siete Congresistas elegidos por el Pleno al inicio de cada período anual de sesiones.

La Comisión Especial Calificadora evalúa la denuncia y determina su procedencia conforme a los criterios dispuestos por el artículo $89^{\circ}$, del Reglamento del Congreso. Estos criterios señalan que la denuncia debe ser presentada por persona capaz, por si o por su representante debidamente acreditado, que la persona que formula la denuncia sea directamente la agraviada por los hechos que se denuncia, que los hechos a que se refiere la denuncia constituyan delitos previstos en la legislación penal y que la denuncia sea dirigida contra funcionarios y ex funcionarios comprendidos en el artículo $99^{\circ}$ de la Constitución Política. Los criterios de evaluación son en realidad normas con rango de ley, de conformidad con el artículo 94, de la Constitución Nacional, y se puede sostener que tiene la jerarquía de Ley Orgánica según lo dispuesto por el artículo $106^{\circ}$ de nuestra ley fundamental.

Pero, lo dispuesto en el Reglamento del Congreso en su artículo $89^{\circ}$, presentan una grave contradicción con la Constitución, cuando determinan que sólo puede denunciar el que sea directamente agraviado. Al respecto se puede preguntar ¿quién es el agraviado cuando se infringe la Constitución?, la respuesta es, sin duda, la Nación, somos todos los peruanos, luego todos los nacionales tenemos legitimidad para obrar o, en este caso, presentar la denuncia constitucional conforme al artículo $38^{\circ}$, de la Constitución que determina que todos los peruanos tenemos el deber de respetar, cumplir y defender la Constitución y el ordenamiento jurídico de la Nación.

En consecuencia, sostenemos que en cuanto a formulación de denuncias por infracción a la Constitución por los operadores supremos del Estado, puede hacerla cualquier peruano.

Luego, las denuncias constitucionales presentadas por los congresistas y las declaradas procedentes por la Comisión especial, son enviadas a la Comisión Permanente, quien nombra de inmediato una Subcomisión para que realice las investigaciones, escuche las declaraciones y testimonios, reúna la información necesaria y presente un informe en el plazo 
que determine la Comisión Permanente; este informe puede concluir con la propuesta de absolución de cargos o de formulación de acusación constitucional ante el Pleno del Congreso. La Comisión Permanente, con el informe que propone la absolución de cargos, procede a votar sin debate. Pero si el informe propone acusación se debate y se vota; con lo que concluye esta primera fase.

La fase de la acusación se inicia con su aprobación; en este caso, la Comisión Permanente nombra una Subcomisión Acusadora integrada por tres de sus miembros, a efecto de que se sustente el informe y formule acusación ante el Pleno del Congreso, finalizando así la etapa de la acusación constitucional.

\subsection{La Resolución Acusatoria o Formación de Causa}

Esta etapa de la Resolución Acusatoria o Formación de Causa, transcurre en el Pleno del Congreso conforme al trámite dispuesto por el artículo $89^{\circ}$ incs. i, j, y k del Reglamento del Congreso de la República. En tal sentido, el Consejo Directivo del Congreso, recibido el informe y la acusación, señala día y hora para el debate de la acusación constitucional.

La Subcomisión Acusadora, en la fecha fijada, sustenta su informe y fórmula la acusación constitucional, con estos antecedentes la Mesa directiva del Congreso abre el debate y concluido éste el Pleno vota. El pronunciamiento puede ser en el sentido de si hay o no lugar a formación de causa como consecuencia de la acusación. En el primer caso, el acusado queda suspendido de sus funciones y sujeto a juicio según ley. En el segundo caso, el expediente se archiva.

La Resolución Acusatoria se pone en conocimiento del Fiscal de la Nación, quien dentro del término de 5 días debe formular denuncia penal ante la Corte Suprema de la República y el Vocal Supremo Instructor nombrado para el efecto, quien abre la instrucción correspondiente; ahora bien, tanto la denuncia Fiscal y el Auto Apertorio, de conformidad con el artículo $100^{\circ}$ de la Constitución, no pueden exceder ni reducir los términos de la Acusación Constitucional. La norma acotada de un lado se presenta con caracteres de naturaleza procesal, pero de otra parte violenta principios constitucionales, especialmente el de separación de las funciones supremas del Estado, artículo $43^{\circ}$, de la Constitución, principio que en orden constitucional asume la categoría de fundamentador y organizador del Estado. Esta disposición del artículo $100^{\circ}$ de la Constitución, contraviene los principios y facultades del Poder Judicial, dispuestos en los artículos $138^{\circ}$ y $139^{\circ}$, así como la autonomía y atribuciones del Ministerio Público, artículos $158^{\circ}$ y $159^{\circ}$.

La misma norma del artículo $100^{\circ}$, de la Constitución, de un lado, otorga funciones jurisdiccionales al Congreso y, por otro lado, le concede facultades sancionadoras; en tal razón, puede imponer sanciones a los operadores supremos, de inhabilitación hasta por 10 años o de destitución de la función, sin perjuicio, además, de cualquier otra responsabilidad, y todo ello como producto de un proceso político, lo que evidentemente desvirtúa la naturaleza del Control Político que se define como la actividad o función esencial del Congreso destinada a preservar la vigencia y funcionamiento del orden político-jurídico del Estado, cuidar el respeto de los Derechos Fundamentales y la consecución de las metas nacionales expresadas en el modelo social. Este control es vinculante, algunas veces reparador, pero nunca sancionador, ni mucho menos puede interferir las funciones de otro órgano del Estado. 
En el proceso del Juicio Político, generalmente, priman las pasiones políticas, por decir lo menos; en tanto que los principios de justicia son dejados de lado y algunas veces el pronunciamiento final es apresurado o interesado, dependiendo de que el acusado pertenezca o no a la mayoría del Congreso. La historia nos da muchos ejemplos en este sentido, Presidentes y altos funcionarios han sido exculpados cuando tenía evidente responsabilidad, $y$, en el caso del aumento de su patrimonio, el Congreso declaró haber formación de causa pero con pruebas poco convincentes.

Pero esta violación contra el principio más importante del Estado Moderno, el de separación de las funciones supremas del Estado, no queda allí, ya que al imponer al Fiscal de la Nación la obligación de acusar al operador supremo, materia del juicio político, ante la Corte Suprema, se interfiere en las funciones del Fiscal de la Nación y con ello estamos presentes ante dos infracciones formales de la Constitución: la violación del principio de separación de poderes, artículo $43^{\circ}$, y el quebrantamiento de la autonomía del Ministerio Público artículo $158^{\circ}$.

Estas violaciones resultan más burdas cuando el artículo $100^{\circ}$ de la Constitución ordena que el Vocal Supremo Instructor abra instrucción y que el auto que apertura el proceso no debe exceder ni reducir los términos de la acusación constitucional, es decir, que el Vocal Instructor no puede hacer el examen de admisibilidad, facultad inherente de la función jurisdiccional, y se le impone una obligación que violenta la función jurisdiccional. En este caso al Vocal Supremo como instructor no se le permite hacer el examen de los hechos y calificar si estos constituyen delitos o no, con lo que se transgrede la potestad que tiene el Poder Judicial de administrar justicia, potestad que el pueblo o nación le ha otorgado artículo $138^{\circ}$ de la Constitución nacional.

La facultad exclusiva de administrar justicia del Poder Judicial, por principio, resulta un elemento esencial de la separación de los poderes del Estado. La independencia del Poder Judicial, artículo $139^{\circ} .2$, obviamente, también resulta gravemente afectada; además, queda desvirtuado el principio del debido proceso. Estas consideraciones, nos llevan a sostener que la fórmula de la Constitución de 1979 , en sus artículos $183^{\circ}$ y $184^{\circ}$, era la más adecuada a la estructura democrática del Estado y a la que se debería volver a fin de preservar el orden constitucional.

Surco, julio de 2013

* Profesor de Derecho Constitucional de la Facultad de Derecho de la URP. 